INTERNATIONAL JOURNAL OF MULTidisciplinARY RESEARCH AND ANALySis

ISSN(print): 2643-9840, ISSN(online): 2643-9875

Volume 04 Issue 11 November 2021

DOI: 10.47191/ijmra/v4-i11-32, Impact Factor: 6.072

Page No.- $1685-1690$

\title{
Technologies for the Production of Machine-Building Composite Polymer Materials and Coatings Working in Contact With Raw Cotton
}

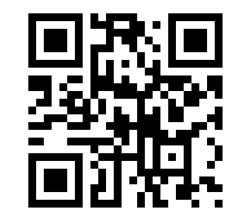

\section{Soyibdzhan Sodikovich Negmatov ${ }^{1}$, Nodira Soyibjanovna Abed ${ }^{2}$, Giyas Gulyamov ${ }^{3}$, Olim Kholikulovich Eshkobilov ${ }^{4}$}

${ }^{1}$ Doctor of Technical Sciences, Prof., Academician of the Academy of Sciences of the Republic of Uzbekistan, Honored Scientist of Uzbekistan, Scientific Director of the State Unitary Enterprise "Fan va Tarakkiyot" of the Tashkent State Technical University named after Islam Karimov. Uzbekistan. Tashkent city.

2Doctor of Technical Sciences, prof., Chairman of the State Unitary Enterprise "Fan va tarakkiyot" of the Tashkent State Technical University named after Islam Karimov. Uzbekistan. Tashkent city

${ }^{3}$ Candidat of technical sciences, Associate Professor of the State Unitary Enterprise "Fan va tarakkiyot" of the Tashkent State Technical University named after Islam Karimov. Uzbekistan. Tashkent city

${ }^{4} \mathrm{PhD}$, Associate Professor of the Department of "General technical disciplines" of the Karshi Engineering and Economic Institute, Uzbekistan, Karshi city

ABSTRACT: Based on numerous analyses of the research results, a technology was developed for obtaining the developed composite thermosetting polymer coatings based on thermosetting polymers-epoxy oligomers ED-20, FAED-20 and FEIS-30 plasticizer, dibutyl phthalate, polyethylene polyamine hardener and industrial waste and organomineral ingredients, as well as a technology for applying antifriction-strength composite polymer coatings for machine-building purposes on metal surfaces of products of various machines and mechanisms.

KEYWORDS: Technology, thermosetting polymer, epoxy resin, plasticizer, dibutyl phthalate, hardener, polyethylene polyamine, industrial waste, organomineral ingredients.

\section{INTRODUCTION}

One of the promising directions in the field of creating highly efficient production of composite thermosetting materials and coatings from them is the development of original technologies for their production, allowing to obtain composite thermosetting polymer materials based on organomineral ingredients from local and secondary raw materials for machinebuilding purposes.

It is known that the operability and durability of the thermosetting polymer materials being developed, which are operated in interaction with fibrous substances, in particular with raw cotton, are determined by electro-thermophysical, antifriction, adhesive strength and microhardness of composite polymer coatings based on thermosetting polymers-epoxy resins. Consequently, composite materials used in friction should differ in a number of features. So, they must, first of all, have high adhesive strength, microhardness, electro-thermal conductivity and low coefficient of friction and electrical resistance, as well as high resistance to interactions with various temperature and aggressive environments.

By regulating electro-thermophysical and antifriction-strength properties, while ensuring high adhesive strength, microhardness, electrical and thermal conductivity, by introducing various organomineral ingredients into the polymer, it is possible to create composite thermosetting polymer materials with high electrical and thermal conductivity, hardness, adhesive and antifriction properties.

It is known [1-3] that the damping properties of antifriction polymer materials are determined by the antifriction properties of the viscoelastic layer, and in turn the damping properties of the viscoelastic layer are determined by the properties of the polymer matrix. Polymer binders for a viscoelastic layer should have a number of features: they must have good adhesion, 
Technologies for the Production of Machine-Building Composite Polymer Materials and Coatings Working in Contact With Raw Cotton

ensure the production of a constantly viscous mass, the glass transition temperature must be located in a given temperature range of the material, high resistance to various aggressive media, for mastic cured materials ensuring the strength of the coating formed.

Objects of research In this regard, for the creation of machine-building composite polymer materials based on organic, inorganic local raw materials from industrial waste, which allows to obtain antifriction composite multiphase materials based on them with high physical and mechanical properties, epoxidian, furan and shale polymers were selected as the source material object [4-6]: ED-16, ED-20, FAED-20 and FEIS-30, and as a hardener of PEP, plasticizer DBF and fillers graphite (gI-2), kaolin and talc [7-8].

Table 1 shows the physical and mechanical properties of antifriction-strength composite polymer coatings for machine-building purposes based on epoxy resin.

Table 1. Properties of antifriction-strength composite polymer coatings for engineering purposes based on ED-20 epoxy resin

\begin{tabular}{|l|l|}
\hline Features & Indicators \\
\hline Adhesive strength, $\sigma_{\mathrm{ad}}, \mathrm{MPa}$ & $8.2-9.0$ \\
\hline Microhardness $\mathrm{H}_{\mathrm{M}, \mathrm{MPa}}$ & $20-30$ \\
\hline Thickness not less than, $\mathrm{mm}$ & $0.2-0.3$ \\
\hline Heat resistance according to Vika, $\mathrm{K}$ & $350-355$ \\
\hline Specific surface electrical resistance, $\mathrm{R}, 10 \mathrm{OM}$ & $17.8-18.0$ \\
\hline
\end{tabular}

Technology for obtaining antifriction- strength composite thermosetting materials. Based on numerous analyses of literature sources [9-12], a technology has been developed for the production of composite thermosetting polymer coatings based on thermosetting polymers - epoxy oligomers ED-20, FAED-20 and FEIS-30, plasticizer, dibutyl phthalate, polyethylene polyamine hardener and industrial waste and organomineral ingredients

As an example, let's consider the technology of obtaining a polymer composition based on ED-20 epoxy resin.

Figure 1 shows the technological scheme for obtaining the created composite thermosetting polymers for machinebuilding purposes.

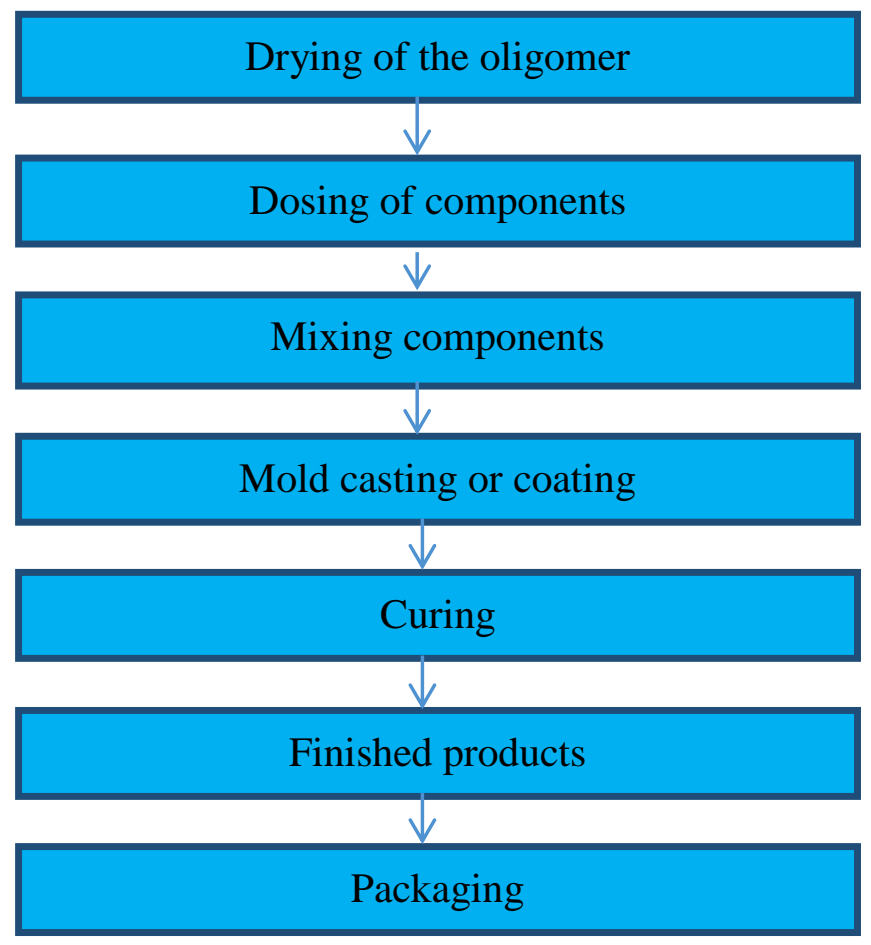

Fig. 1. Technological scheme for obtaining composite thermosetting polymer coatings.

According to this scheme, the volume of the composition is determined by the size and quantity of the structural element. The estimated amount of epoxy oligomer ED-20 and fillers is dried in a drying cabinet to remove moisture at a temperature of $373 \mathrm{~K}$ for 2 hours. 
Technologies for the Production of Machine-Building Composite Polymer Materials and Coatings Working in Contact With Raw Cotton

The oligomer is cooled to $323-333 \mathrm{~K}$. Then the dosing procedure is carried out, that is, all components are weighed in calculated quantities, according to the technological modes of obtaining anticorrosive epoxy composite materials given in Table 2.

Table 2. Technological modes of obtaining antifriction- strength epoxy composite coatings for engineering purposes based on ED-20 epoxy resin

\begin{tabular}{|l|l|l|}
\hline Name of operations & $\begin{array}{l}\text { Temperature } \\
\text { mode, K }\end{array}$ & Time, min \\
\hline Drying of resin and fillers & $373-375$ & 120 \\
\hline Dosing of resin, DBF and fillers & 300 & - \\
\hline Mixing ED-20 with DBF & 300 & $8-1$ \\
\hline Mixing of ED-20, DBF with filler & $320-325$ & $8-10$ \\
\hline Cleaning and anti-adhesive treatment of the mold & 300 & - \\
\hline Mixing of ED-20, DBF filler with hardener & $295-300$ & 10 \\
\hline Pouring the finished mixture into molds & 300 & 5 \\
\hline Curing of compositions in a thermal cabinet under the & 330 & 120 \\
\hline Cooling of compositions in a thermal cabinet & Дo 300 & - \\
\hline Storing compositions & $270-310$ & - \\
\hline
\end{tabular}

To obtain coatings for machine-building purposes based on ED-20 epoxy resin, the first plasticizer DBF is added to the epoxy resin. The mixture is thoroughly mixed with an electric mixer until a homogeneous mass is obtained. Then graphite, kaolin, and talc fillers are added to the mass in the calculated amount. The mixture is also thoroughly mixed until the fillers are completely wetted with a binder.

Complete wetting of filler particles with a binder is determined by the complete cessation of the release of air bubbles from the mixture. To speed up the process, the mixture is heated to a temperature of $353-360 \mathrm{~K}$ and a PEP hardener is introduced. The mixture is thoroughly mixed until a homogeneous mass is obtained for $10-15$ minutes continuously. The viability time of the finished mixture is only 25-30 minutes. Therefore, the compositions are obtained in small batches from 2 to $5 \mathrm{~kg}$ and the mixture is immediately cast into pre-prepared and treated with an anti-adhesive substance, molds having the shape of structural elements and coated on the working surface of the products.

The cast polymer compositions are cured at a temperature of $350 \mathrm{~K}$ for 4-6 hours in a thermal cabinet. Cooling of compositions is carried out together with a thermal cabinet to room temperature. Then the structural elements or the coated part or products are removed from the mold and packed in plastic bags and sent for testing or intended use.

Technology for obtaining antifriction- strength epoxy composite coatings for engineering purposes from thermosetting composite materials.

The schematic diagram of the technological line for the production of antifriction machine-building composite materials developed on the basis of the sequence of the stage of technological processes is shown in Figure 2 [9-13].

As can be seen from Figure 2, first of all, the technological stage provides for the preparation of components of compositions from a binder, filler, plasticizer and hardener, as well as their supply to the appropriate units. Mixing of the components is carried out in three or two stages. To obtain an antifriction composite material, the starting material is an epoxy resin of the appropriate brand, which is poured into a container 1 to a certain volume. Then, by opening the valve 21 through the dispenser 2, the required amount of oligomers is transferred to the site 3 where it is subjected to heat treatment for two hours from where it is sent to the mixing site 4 . At the same time, at the mixing site 4, a plasticizer is sent through the hopper 6 and dampers 22, measuring devices 9. Mixing of the oligomer with the plasticizer lasts 5-10 minutes, then the composition in the 

Contact With Raw Cotton

required volume is sent through the dispenser 5 to the site 14 , then through the container 7 , dampers 23 , dispensers 10,13 and separator 12, fillers are introduced in portions and mixed for 30-40 minutes and sent through measuring devices 15 to the site 16 for mixing ingredients (oligomer) At the third stage, the hardeners from the container 8 , the flap 24, the dispenser 11 are sent to the site 16 , where the above components are mixed. The mixing time is $20-30$ minutes. It should be noted that after mixing, the finished composition of the antifriction coating is unloaded into a storage container 25 . Further technological processes of mixing the components of the antifriction compositions proceed sequentially as shown in Figure 2.

At the coating site 17, an antifriction composition is applied to the prepared surface of the part using a spatula.

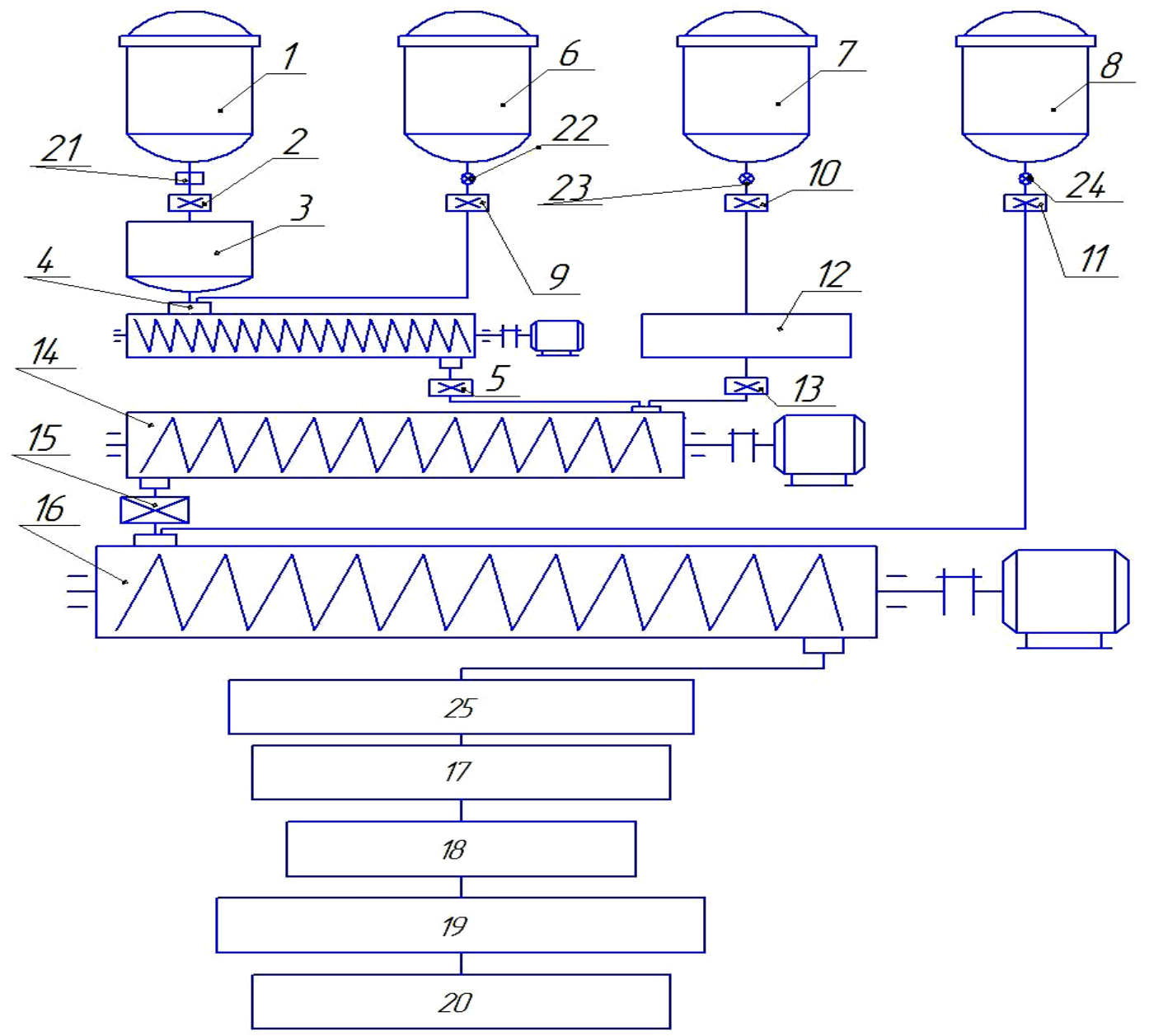

1, 6, 7, 8-container for starting materials: epoxy resins, plasticizers, fillers and hardeners, respectively;. 2, 5, 9, 10, 11, 13, 15dispensers. 3-a site for heat treatment. 4, 14, 16-mixing units. 12-installation for separation. 17-an area for applying an antifriction coating. 18-a site for heat treatment. 19-the section of cold curing of coatings with compositions of the part. 20warehouse of finished products. 21-valve. 22, 23, 24-dampers, 25-storage tank for antifriction KPM and coating

Fig. 2. Diagram of the technological line for the production of antifriction engineering composite polymer materials based on thermosetting polymers (epoxy resins)

A part with an anti-friction coating is placed on a rack and sent to the finished product ware house 20. Complete curing of the composition under normal conditions occurs within 24 hours, after which the part is completely ready for use. The production of antifriction materials does not require large energy costs.

The technological process of obtaining a pilot batch of antifriction machine-building composite polymer materials was carried out on the created technological line shown in Figure 23. with the specified technological modes, consisting in the following: the starting material, epoxidian, epoxifuran or epoxyslanec resins of the corresponding brand is poured into a container to the full volume. Then, by opening 21 valves through the dispenser 2 , the required amount of oligomers enters the site 3 where it is subjected to heat treatment (at $370 \mathrm{~K}$ ) for two hours from where it is sent to the mixing site 4 . At the same time, the required amount of plasticizer is sent to the site 4 through the hopper 6 filled to a certain volume and the damper 22 , into the measuring devices 9. The mixing of the oligomer with the plasticizer lasts 20 minutes, then the composition in the required volume is sent through the dispenser 5 to the site 14. Further, fillers are introduced in portions through the container 

Contact With Raw Cotton

7, dampers 23 , dispensers 10,13 and separator 12 , and mixed for 30-40 minutes and sent through measuring devices 15 to the site 16 for mixing with ingredients (oligomer). Then, the hardeners from the container 8, the flap 24, the dispenser 11 are sent to the site 16, where the above components are mixed. It should be noted that after the introduction of each ingredient, the composition was mixed for 20-30 minutes until a homogeneous composite material was obtained. After mixing, the finished antifriction composition (mixture) pretreated with an anti-adhesive substance was cast into a storage container 25 . The reactive mass was cured at $300 \mathrm{~K}$ (FAED-20 at $350 \mathrm{~K}$ ) for 10 hours. Samples from ED and EIS were subjected to heat treatment at $373 \mathrm{~K}$ for 4 hours, and samples from FAED - at $400 \mathrm{~K}$ for 6 hours.

The technology of applying the composition to the surface of equipment and installations. Preparation of the metal surface of equipment and installations operating in contact with an aggressive environment is carried out as follows. First, corrosion products are removed from the metal surface using metal brushes and sandpaper. Then it is necessary to degrease the surface with acetone and treat it with a rust converter $\mathrm{N}_{3}$. It is a mixture of $40 \%$ orthophosphoric acid $\left(\mathrm{H}_{3} \mathrm{PO}_{4}\right)($ density 1.685 $\mathrm{g} / \mathrm{cm}^{3}$ ) and zinc 90 by 10 mass parts, respectively. It can be obtained directly at the place of application. This requires acid dishes, the volume of which is 3-4 times larger than the volume of the components being mixed, since the reaction of acid with zinc is accompanied by foaming due to the release of hydrogen. Consumption per $10 \mathrm{~kg}$ of rust converter is $3-9 \mathrm{~kg}$ of orthophosphoric acid and $1 \mathrm{~kg}$ of zinc dust.

The converter is prepared as follows. In the calculated amount of acid, with constant stirring, the calculated amount of zinc dust is gradually introduced. The reaction of the interaction of the components lasts up to 10 hours and is accompanied by the release of heat. Срок хранения преобразователя не ограничен.

Consumption per $1 \mathrm{~m} 2$ of the surface is $1.5-2 \mathrm{~kg}$, depending on the thickness of the rust layer. The rust converter is applied to the surface with a brush in a thin layer, rubbed with a double shading method for better impregnation of the rust layer. The presence of moisture on the treated surface is not an obstacle to the application of the converter. At an average daily temperature of $288-290 \mathrm{~K}$ and a relative humidity of $75 \%$, the drying time is a day. During this time, the reaction between the converter and the corrosion products ends. With this, the operation of preparing the metal surface ends and it is ready for applying a composite anticorrosive material.

The next stage is the application of the finished composition. It is carried out in two ways manually or mechanized;

-the prepared compositions are manually applied to the metal surface of equipment or installations using brushes evenly and thoroughly rubbed over the surface;

- in a mechanized way, it is advisable to apply anti-polymer compositions to large open surfaces - metal structures or containers with the help of an airless spraying unit "Raduga-063P;

- the installation is designed for painting products by airless spraying at high pressure, the characteristics of which are presented in Table 3.

Table 3. Technical characteristics of the installation "Raduga- 0 63P"

\begin{tabular}{|l|l|}
\hline Specifications & Indicators \\
\hline Maximum static pressure, $\mathrm{P}, \mathrm{MPa}$ & 22.0 \\
\hline Maximum operating pressure $\mathrm{P}, \mathrm{MPa}$ & 19.0 \\
\hline Efficiency, kg/min & 0.63 \\
\hline Compressed air operating pressure $\mathrm{P}, \mathrm{MPa}$ & $0.01-0.05$ \\
\hline Air consumption at $\mathrm{P}_{\text {Max }}>\mathrm{m}^{3} /$ hour & 20.0 \\
\hline High pressure hose length, $\mathrm{m}$ & 15.0 \\
\hline Dimensions: length,sm & 80 \\
width,sm & 42 \\
height,sm & 42 \\
\hline
\end{tabular}

The antifriction-strength compositions applied on the surface are cured within 20-24 hours at a temperature of $290 \mathrm{~K}$. After curing, the thickness of the coatings is measured with a micrometer (MK-120).

\section{CONCLUSIONS}

A technology has been developed for the production of effective electro-heat-conducting and antifriction-strength polymer composite materials and coatings based on ED-20 epoxy oligomer and industrial waste. 
Technologies for the Production of Machine-Building Composite Polymer Materials and Coatings Working in Contact With Raw Cotton

The technology of applying composite polymer coatings for machine-building purposes to the working surfaces of machines and mechanisms operating in interaction with raw cotton in the conditions of cotton gins has been developed.

\section{REFERENCES}

1) Alent'ev A.Yu., Yablokova M.Yu. Binders for polymer composite materials. -M .: Lomonosov Moscow State University, 2010 .-- $69 \mathrm{p}$

2) Ananin S.V., Ananyeva E.S., Markin V.B. Composite materials. -Ch. 2. Barnaul: AltSTU, 2007. - 94 p.

3) Adamenko N.A., Fetisov A.V. and other Structural polymer composites. - Volgograd: VolGTU, 2010 .- 100 p.

4) Mashkov Yu.K. and other Structural plastics and polymer composite materials. - Omsk: OmSTU, 2002 .-- 129 p.

5) Mikhailin Yu.A. Structural polymer composite materials. - St. Petersburg: NOT, 2010 .-- $822 \mathrm{p}$.

6) Kryzhanovsky V.K., Burlov V.V., Panimatchenko A.D. and other Technical properties of polymeric materials. - M .: Profession, 2003. - $240 \mathrm{p}$.

7) Panova L.G. Fillers for polymer composite materials. - Saratov: SSTU, 2010 .-- 68 p.

8) Ivanov V.A. A systematic approach to the creation of antifriction materials and friction units. - Khabarovsk: Pacific State University, 2015 --- 239 p.

9) Andreeva A.V. Fundamentals of physical chemistry and technology of composites. - M .: IPRZhR, 2001.-192 p.

10) Bazhenov S.L. Mechanics and technology of composite materials. - Dolgoprudny: Intellect, 2014 .-- 328.

11) Bataev A.A., Bataev V.A. Composite materials: structure, production, application. - Novosibirsk: NSTU, 2002 .- 384 p.

12) Kerber M.L. and other Polymer composite materials. Structure, properties, technologies. - St. Petersburg: Profession, 2008 .-- $560 \mathrm{p}$.

13) Kerber M.L., Bukanov A.M., Wolfson S.I. and other Physical and chemical processes in the processing of polymers. - St. Petersburg: Scientific bases and technologies, $2013 .--320 \mathrm{p}$. 